\title{
Comments on the Blackwood Inquiry
}

John H.M. Crichton

In September 1991 the Special Hospitals Service Authority set up an inquiry, under the chairmanship of Professor Herschel Prins, to investigate the death of a Broadmoor patient, Orville Blackwood, and to review in the light of this case two other deaths at Broadmoor of AfroCaribbean patients, Michael Martin and Joseph Watts (SHSA, 1993). From the outset the approach of this inquiry was fundamentally different from other recent investigations of the special hospitals; most notably it followed a less formal pattern than the Ashworth Inquiry (HMSO, 1992) which was going on at the same time. The focus was not on individual complaints or upon blame for them, but instead on the patterns of practice within Broadmoor which contributed to the tragic deaths of three patients. This report is no less hard-hitting in its recommendations than the Ashworth Inquiry, but it nevertheless managed its investigation in a way which sought to encourage staff to contribute and made recommendations which aimed to avoid scapegoating. Like Ashworth, the Blackwood Inquiry is not only important to forensic psychiatry but is relevant to all aspects of psychiatric work.

\section{The case of Orville Blackwood}

The first part of the report describes in detail the history of Orville Blackwood. He was a large Afro-Caribbean man born in Jamaica but who had moved to London at an early age. He had been in trouble with the police from an early age and by his 20 s had convictions for several minor criminal offences and had served two sentences of a few weeks in prison. From 1982, at the age of 22 , there was the start of a remitting and relapsing psychotic illness. Over the following two years Blackwood had nine, mostly compulsory, admissions to local psychiatric hospitals. His condition attracted several different diagnoses, including acute paranoid state, drug induced psychosis, acute situational psychosis and psychotic reaction in an inadequate personality.

In January 1986, shortly after serving a six month sentence for actual bodily harm and criminal damage. Blackwood was arrested for robbing a bookmakers shop with a toy gun. It was suggested that he should have been admitted to the Denis Hill medium secure unit at Bethlem Royal Hospital, but since no bed was available he was sentenced to three years imprisonment. Within a year his mental state had deteriorated so seriously he was transferred to the Denis Hill unit.

In October 1987, after a settled period, Blackwood became disturbed after a trivial incident and seriously assaulted a nurse. The police were required to restrain him and transfer was arranged to Broadmoor. At Broadmoor he presented problems in management especially when he refused medication, but he did respond to fairly large doses of neuroleptics and when he was well was popular among staff and patients. He was always described as lacking insight and was bitter that he remained in hospital after the end of his custodial sentence. By 1991 there were moves for Blackwood to be transferred back to the Denis Hill unit and a Mental Health Review Tribunal had adjourned to further consider his case.

At the beginning of August 1991 Blackwood became unsettled and demanding; he set off the fire alarm, blocked his sink and was abusive to his consultant. He was managed by being placed in seclusion where damage was done to the inside of the room. On 28 August the ward doctor prepared to review Blackwood in his side room. Blackwood was quietly lying on his bed when the doctor entered into his room, allegedly without a knock or warning; there were nurses outside should he become violent. Blackwood allegedly tried to punch the doctor and was restrained. The doctor decided to administer Sparine $150 \mathrm{mg}$ and Modecate $150 \mathrm{mg}$ intramuscularly. The staff left the room after the administration of injections, but soon observed from outside that Blackwood had stopped breathing. Cardiopulmonary resuscitation was unsuccessful.

The report made serious criticisms about the way Orville Blackwood's relatives were subsequently told of his death. Such criticisms were also made by the Ashworth Inquiry about how relatives were told of Sean Walton's death and by Miss Ritchie, $\mathbf{Q C}$, in her report about the death of Michael Martin (SHSA, 1989). 


\section{Orville Blackwood's death}

The committee felt that there was a knee-jerk response to patient misdemeanour and violence. Seclusion and intramuscular medication was the standard response with several members of staff available if needed. Blackwood's increased irritability was partly understandable because of the tension from his Tribunal being adjourned, but this did not seem to be appreciated by staff. The committee found that the staff insufficiently used wider psychiatric skills to prevent and treat Blackwood's worsening mental state. The tension between safe incarceration and treatment is also expressed in the Ashworth Inquiry and both reports concluded that the emphasis has rested too heavily on the former. Perhaps it is unreasonable to ask nurses to be both 'warder' and therapist. In some secure hospitals in the United States there are separate nursing and security staff.

There has been much debate about the role of the intramuscular injections in the sudden death of psychiatric patients. The committee heard detailed evidence on this point, including the theory that the pharmacokinetics of phenothiazines are so effected when a patient is in an excited state as to make them much more cardiotoxic. The committee could not be conclusive but suggested the need for urgent research into this, especially since special hospital patients are often given very large amounts of psychotropic medication.

\section{Similarities between the deaths of Orville Blackwood, Michael Martin and Joseph Watts}

All of these Afro-Caribbean patients died in seclusion where they were placed after disagreements with other patients or members of staff which had led to them being violent. They had all been diagnosed schizophrenic and they had all been following an unhealthy diet. Orville Blackwood weighted 21 stone and despite a diagnosis of diabetes mellitus at one time still consumed large amounts of Coca Cola and chocolate. Joseph Watts was 19 stone and Michael Martin had a 'passion for chocolate' and was described as heavily built at post mortem. The report makes suggestions that the SHSA investigate how the lifestyle of patients could be made healthier.

All three patients had the reputation of being likeable when well, but they also generated a fear of violence in the staff. The committee received the impression of 'big, black and dangerous' so frequently in their inquiry that they incorporated it, with a question mark, as their sub-title. The committee investigated the question of whether staff had been racist in their treatment. They suggest that there was a racial institutional bias against ethnic minorities, but this was not by direct acts of racism, rather by acts of omission. They quote a Health/Home Office paper which states, "the 'colour blind' approach of some ignores issues of race and culture and the experience of racism". The report states, "The experience of Afro-Caribbean inner-city youngsters is not fully understood by Eurocentric psychiatry and those who work in the psychiatric system. It is important that differences are recognised and catered for" (page 51).

\section{Conclusions}

The report made 47 recommendations for action and invited themselves back to monitor progress if the SHSA agreed: in the event they did not. The report received wide media coverage and despite a second print run the SHSA has no more copies available. The task of the special hospitals is perhaps the most difficult in the whole of psychiatry and the numerous reports and inquiries about them reflect that difficulty. This report offers constructive criticism and the survival of the special hospitals depends on how such criticism is heeded.

\section{References}

DepartMent OF Health/Home Office (1992) Revtew of Health and Soctal Service for Mentally Disordered Offenders and Others Requiring Similar Services. Services for People from Black and Minority Ethnic groups: issues of race and culture. London: Department of Health/Home Ofice.

HMSO (1992) Report of the Committee of Inquiry into Complaints about Ashworth Hospital (Cmnd 2028). London: HMSO.

SHSA (1989) Report of the Inquiry into the Circumstances Leading to the Death in Broadmoor Hospital of Mr Joseph Watts on 23 August 1988. London: Special Hospitals Service Authority.

-(1993) Report of the Committee of Inquiry into the Death of Broadmoor Hospital of Orville Blackwood and a Review of the Deaths of Two Other Afro-Cartbbean Patients. 'Big. Black and Dangerous?'. London: Special Hospitals Service Authority.

John H. M. Crichton, Nightingale Research Scholar and Honorary Registrar in Psychiatry. University of Cambridge, Institute of Criminology, 7 West Road, Cambridge CB3 9DT 